\title{
DEL CAMPO AL GABINETE LA OBRA CARTOGRÁFICA DEL AGRIMENSOR E HIDRÓMETRA FRANCISCO APARISI Y FERRANDIS (VALENCIA, 1732-1806)
}

\author{
Alfredo Faus Prieto \\ Doctor en Geografía \\ IES Francesc Ferrer i Guàrdia (Valencia)
}

\section{RESUMEN}

La cartografía de agrimensura e hidrometría ha recibido poca atención en una historia de la cartografía basada tradicionalmente en el estudio de las grandes figuras y de los mapas y planos que realizaron. Sin embargo, se trata de una cartografía que sirvió de base a la realizada por los ingenieros militares, los arquitectos y los geógrafos y que, además de estar presente en el mundo judicial, acompañó a los grandes proyectos técnicos del siglo XVIII. En este artículo se defiende la necesidad de un enfoque contextual y sociológico de la historia de la cartografía que reivindique el trabajo de los colectivos de mapistas olvidados. Siguiendo este enfoque, se realiza una aproximación a los métodos de trabajo de los mapistas agrimensores y se estudia, a modo de ejemplo, la obra cartográfica del agrimensor valenciano Francisco Aparisi y Ferrandis.

Palabras clave: Historia de la cartografía, enfoque contextual, agrimensura, Reino de Valencia, siglo XVIII.

\section{ABSTRACT}

The cartography of survey and hydrometry has received few attentions in a history of the cartography based traditionally on the study of the big figures and of the maps and planes that they realized. Nevertheless, it is a question of a cartography that it used as base the realized one for the military engineers, the architects and the geographers and that, besides being present in the judicial world, he accompanied to the big technical projects of the 18th century. In this article there defends itself the need of a contextual and sociological approach of the history of the cartography that claims the work of the groups of cartographes forgotten. Following this approach, an approximation is realized to the methods of work of the cartographes land-surveyors and there is studied, like example, the cartographic work of the Valencian land-surveyor Francisco Aparisi y Ferrandis.

Key words: History of the cartography, contextual approach, survey, Kingdom of Valencia, 18th century. 


\section{Introducción}

En la historia de la cartografía se ha venido utilizando el método de las grandes figuras para cubrir cronologías muy amplias con una información muy escasa. La recopilación ritual de datos biográficos y de algunos documentos sueltos ha permitido que determinadas personas o piezas cartográficas se convirtieran en puntos nodales de la misma, a pesar de que apenas se sabía nada de ellas. El resultado ha sido una crónica lineal, simplificada en extremo, en la que se encadenan sin solución de continuidad sucesivos hitos cartográficos. En el caso de la cartografía valenciana anterior al siglo XIX, esta función la han cumplido una docena de mapas y planos impresos y una lista reducida de grandes autores en la que se incluyen Abraham Oertel, Antonio Manceli, Francisco Antonio Cassaus, Tomás Vicente Tosca, Tomás López de Vargas y Antonio José Cavanilles. Aunque este recurso ha tenido la virtud de despertar el interés por unos materiales que habían permanecido ocultos durante demasiado tiempo, también ha obstaculizado la investigación al reducir una historia rica en contrastes a una sucesión de hechos puntuales alejados del contexto general.

La alternativa a la que nos adherimos pasa por una revisión metodológica basada en fuentes de archivo que permita comprender mejor la posición y el objeto de la cartografía a lo largo de la historia. La sustitución del modelo de grandes figuras por otro contextual, sociológico, debería favorecer el reconocimiento del valor intrínseco de la cartografía y rescatar del olvido a determinados colectivos profesionales que la tuvieron como herramienta cotidiana de trabajo (Thrower, 2002; Harley, 2005). Ampliar la nómina de mapistas y conocer cuál era su formación y cómo trabajaban (contexto de realización), así como averiguar el origen, el coste y la finalidad de los mapas y planos que hicieron (contexto de $u s o$ ), son objetivos ineludibles en esta dirección. Enfocada desde esta perspectiva, la historia de la cartografía se convierte en la historia de los profesionales que la ejercieron. El resultado es una transformación radical: frente a la excepcionalidad, la práctica diaria; frente a unos cuantos planos grabados e impresos, centenares de ellos levantados sobre el terreno y que no tuvieron tanta fortuna; frente al carácter episódico de los primeros, el uso habitual de los segundos en campañas militares, proyectos técnicos y pleitos.

Este enfoque es particularmente apropiado a la hora de atender la actividad de un colectivo como el de los mapistas agrimensores, olvidado en la historiografía debido a la escasa relevancia social de sus miembros, la posición marginal que ocupaba entre los grupos que surgieron en el siglo XVIII del tronco común de las ciencias físico-matemáticas, su tardía consolidación institucional y una actuación que estuvo limitada, básicamente, al ámbito local (Thompson, 1968). Sólo a partir de la reivindicación del trabajo de técnicos como Francisco Aparisi y Ferrandis parece posible superar este obstáculo y situar al colectivo en el lugar que merece en la historia de la cartografía. Baste decir al respecto que la mayoría de los mapas y planos impresos valencianos anteriores al siglo XIX fueron una copia o se basaron en otros manuscritos levantados por autores como el que nos ocupa. Así ocurrió, por ejemplo, con el conjunto incluido en las Observaciones de Cavanilles, una obra capital en la que se encuentra una copia del mapa de la baronía de Chulilla que Aparisi realizó, junto a José Cervera y Juan Bautista Mínguez, en 1772. Rastrear su actividad cartográfica y enmarcarla en el contexto en el que se produjo no deja de ser, en último término, un ejercicio de justicia histórica. 


\section{Cartografía y agrimensura en el siglo XVIII}

\subsection{Colectivos de mapistas}

Aunque comúnmente se denominase geógrafo a cualquier persona capaz de realizar un levantamiento cartográfico (el término cartógrafo no empezó a usarse hasta finales del siglo XIX), durante el siglo XVIII la cartografía española estuvo en manos de cinco corporaciones profesionales distintas: geógrafos, ingenieros militares, marinos, arquitectos y agrimensores (Capel, 1982). Con la única excepción de los geógrafos, estas corporaciones se diferenciaban entre si por las titulaciones que exhibían sus miembros. Mientras los ingenieros militares y los marinos ostentaban la graduación que habían obtenido en las academias de sus cuerpos de origen (las de Barcelona, Orán y Ceuta, en el primer caso, y la de Cádiz, en el segundo), los arquitectos y los agrimensores sólo tuvieron acceso a un título académico específico tras la creación de las academias reales de bellas artes de San Fernando (Madrid, 1751) y de San Carlos (Valencia, 1768), respectivamente.

Desde el punto de vista que nos interesa, estas corporaciones también se distinguían por las características de los mapas y planos que realizaban. Los geógrafos propiamente dichos estaban al cuidado de una cartografía erudita: mapas a pequeña escala de España, de sus reinos o de las posesiones de ultramar, hechos a partir de materiales anteriores que se reelaboraban continuamente en estudio. Su trabajo consistía en la recopilación paciente de una información que luego debían trasladar, previa conversión de medidas, al plano. De los ingenieros militares y los marinos se esperaba, en cambio, que cubriesen el vacío provocado por la ausencia de una política cartográfica coherente en los siglos precedentes. De los primeros, organizados bajo la dirección de Jorge Próspero de Verboom, dependían las defensas terrestres y las obras públicas que la ingeniería civil no podía atender; de los segundos, miembros de un cuerpo renovado a iniciativa de José Patiño, la defensa naval y las relaciones con las colonias. De ambas actuaciones se derivó la cartografía mejor concebida de todo el siglo: proyectos de obra y fortificación, mapas de navegación y derroteros marítimos. Los arquitectos y los agrimensores, por último, se centraron en proyectos de construcción que solían incluir la delineación de perfiles y planos y en encargos que llevaban aparejada una cartografía a gran escala vinculada a los ámbitos municipal y judicial.

Miembros de todos estos colectivos actuaron en el antiguo Reino de Valencia, recibiendo la denominación común de mapistas cuando sus trabajos iban acompañados de mapas y planos. Sin embargo, su relación con estas tierras era muy distinta. La presencia de geógrafos, ingenieros militares y marinos respondía a encargos ocasionales de larga duración (la construcción del Camino Real de Madrid, la mejora del Puerto de Valencia o la prolongación de la Acequia Real del Júcar, entre los mayores), que a menudo dirigían desde la distancia tras una breve estancia sobre el terreno. Esta situación les obligaba a ayudarse de expertos locales y a delegar la plasmación definitiva de sus proyectos en arquitectos y agrimensores. Dado que estos últimos también atendían los cometidos más cotidianos (la reforma de un edificio, el reparto de herencias, la medición y compra-venta de terrenos, la canalización de aguas, los pleitos sobre límites de propiedad y/o jurisdicción, etc.), la inmensa mayoría de los mapas y planos valencianos del siglo XVIII llevan su firma. Puede decirse que mientras la actividad de los geógrafos, los ingenieros militares y los marinos respondía a una concepción de Estado (se desplazaban por el territorio nacional según las necesidades), la de los arquitectos y agrimensores lo hacía a otra de carácter periférico.

En el caso del colectivo valenciano de agrimensores, la abundancia y la calidad de esta cartografía periférica es sorprendente porque estamos ante un grupo de técnicos que debió competir duramente para conseguir un espacio profesional propio. Hasta mediados 
del siglo XVIII, este colectivo careció de cualquier tipo de regulación, siendo la mayoría de sus miembros simples expertos en agricultura. Aunque nunca formaron un gremio, su actuación puede calificarse como paragremial: detentadores exclusivos de los empleos municipales y judiciales, los transmitían de generación en generación en el seno de su propia familia (los Fos, Casamayor, Ausina o Romero de la huerta de Valencia) e impedían, de este modo, la movilidad profesional y cualquier atisbo de competencia. La situación no cambió hasta los años sesenta, cuando la necesidad de garantizar la preparación de los peritos llevó, tras la creación de la Real Academia de Bellas Artes de San Carlos, a la instauración de un examen de aptitud como paso previo al ejercicio de la profesión. El título académico, específico y normalizado de agrimensor que recogían sus estatutos venía a sustituir a las credenciales libradas hasta entonces por municipios y tribunales de justicia. Entre 1768 y 1808 obtuvieron este título un total de 311 agrimensores, dos terceras partes de los cuales eran de origen valenciano (Bartolomé Coltell, Pedro Torres, Roque Girona, Pedro Pablo Olmos, etc.). Sólo entonces estos titulados pasaron a tener competencias exclusivas sobre el sogueo de parcelas, el deslinde de términos y propiedades o la nivelación de terrenos para la conducción de aguas, trabajos todos ellos que iban acompañados, por lo común, del levantamiento de mapas, planos y perfiles de nivelación (Faus, 2001).

\subsection{El trabajo del mapista agrimensor}

Además de los anteriores, entre los encargos propios de los agrimensores se encontraban las excavaciones y desmontes, el aforo de líquidos, la medición y tasación de tierras, la división de herencias y el cálculo de distancias inaccesibles. Esta diversidad justifica la presencia de agrimensores en la dirección de proyectos de obra, la redacción de dictámenes técnicos o la resolución de litigios jurídicos. También explica la especialización interna que se produjo de manera irreversible en el colectivo como consecuencia del grado de dificultad de dichos encargos. La excavación y el desmonte de terrenos quedó en manos de peones sin cualificación; el justiprecio y la división de herencias pasó a ser competencia de los expertos en agricultura que no alcanzaron la titulación; el apeo y el amojonamiento de términos se convirtió en una parcela reservada a los agrimensores más genuinos; la nivelación de terrenos para la conducción de aguas, en fin, devino en un asunto de técnicos muy especializados o hidrómetras. Aunque la mayoría de estas tareas tenían una larga tradición en el Reino de Valencia, sólo en el siglo XVIII se vincularon a una corporación profesional plenamente consolidada (Faus, 1995).

La importancia de estas actuaciones se acrecentó durante la centuria a causa de la expansión del regadío y del inicio de innumerables litigios de carácter territorial. Así, se multiplicaron los encargos ligados al mantenimiento de una red de acequias de origen medieval, su extensión a zonas de secano, el empadronamiento de las parcelas beneficiadas por el riego, el deslinde de ámbitos de contornos cambiantes y administradores mal definidos como las riberas de los ríos, la delimitación de propiedades, su justiprecio en operaciones de compra-venta o divisiones por herencia, y el control de los asentamientos ilegales. Trabajos todos ellos que podían conducir al levantamiento de mapas y planos. La certidumbre de que un gran número de pleitos podría haberse evitado de existir una representación exacta de los límites jurisdiccionales o de propiedad convirtió la actividad cartográfica de los agrimensores en una necesidad ineludible. Y lo mismo sucedió con los dictámenes técnicos: proyectar una acequia podía ser un ejercicio inútil si no iba acompañado de los perfiles topográficos producto de la nivelación del terreno. La figura del mapista era, por este motivo, inseparable de la del agrimensor. 
No obstante, los resultados podían ser muy dispares. Representar un término o parcela a escala estaba fuera del alcance de muchos agrimensores, como lo prueba el hecho de que de los más de trescientos que se titularon por la Real Academia de San Carlos entre 1768 y 1808 sólo cinco de ellos se examinaron a voluntad propia de pruebas de planimetría y obtuvieron la licencia, preceptiva desde 1784, para el levantamiento de mapas y planos. El contraste entre esta penuria y la creciente demanda de buenos mapistas provocó una nueva subdivisión interna en el colectivo de agrimensores. Los técnicos mejor preparados pudieron acceder a los encargos mejor remunerados, en los que era obligatoria la delineación de mapas y planos; la generalidad de ellos, sin embargo, tuvo que conformarse con trabajos secundarios en los que su consideración no era muy diferente de la que merecía un experto en agricultura.

\subsubsection{El trabajo de campo}

El instrumental con el que trabajaban los agrimensores era muy reducido, a pesar de la variedad de útiles existente (Ludovico, 1991). Dado que los mejores instrumentos (pantómetra, grafómetro, alidada, etc.) estaban fuera de su alcance, en el campo solían calcular las medidas lineales con la ayuda de varas, cañas, sogas o cadenas, las medidas angulares con el auxilio de la plancheta y el semicírculo graduado, y la inclinación de los terrenos con el empleo de niveles de tranco o de agua. En cualquiera de estos menesteres utilizaban, además, la escuadra, el cartabón y el cuadrante. Las dificultades que tenía la mayoría de los agrimensores para manejar los instrumentos más complejos era consecuencia directa de la ausencia de cauces de formación. La inexistencia de centros extrauniversitarios dedicados a la enseñanza de las matemáticas y la lenta institucionalización académica del oficio justifican que su forma de trabajar no sufriese grandes modificaciones a lo largo del siglo. Con gremio o sin él, aprender la profesión sólo era posible trabajando junto al padre o un perito vecino (endotecnia).

Como resultado de lo anterior, la mayoría de los mapas y planos de agrimensura tuvieron su origen en operaciones rudimentarias de medición (Hijosa, 1791). El primer borrador se hacía normalmente a ojo. Al tiempo que se iban colocando las estacas que servían para demarcar el terreno, el perito se hacía una idea de su forma y la trasladaba al papel, trabajo que resultaba más fácil si existía algún otero desde el que pudiera verse completo o algún levantamiento anterior. Sobre este apunte anotaba los resultados de la medición y dibujaba la descomposición en polígonos rectilíneos de toda la figura. La triangulación consecuente podía hacerse de dos maneras: si sólo se disponía de una cuerda o de una cadena, se realizaba a partir de un punto central del terreno, dirigiendo las visuales hacia los ángulos señalados con jalones; si se utilizaba una escuadra o un cartabón, bastaba con tirar sobre el borrador una línea transversal semejante a la ideada para correr el instrumento en el campo. Conocidos los lados, todo se reducía a trasladarlos según una escala predeterminada, que podía establecerse a partir de la línea tomada como base. La escuadra y el cartabón también facilitaban el levantamiento del plano de un terreno inaccesible. Para ello, se inscribía en una figura conocida, se dibujaba a escala y se eliminaban luego los espacios sobrantes, también convertidos en polígonos.

Sólo los mejores mapistas utilizaban la plancheta. Se trataba de una tabla unida al terreno por medio de un trípode, que se orientaba y nivelaba gracias a un juego de tornillos y niveles, y que se completaba con una alidada de pínulas para proyectar visuales. Su uso era el siguiente: una vez medida una línea de base con cuerda, se trasladaba a escala al papel que se colocaba sobre la tabla y desde ella se dibujaban las líneas que marcaban las pínulas, dirigidas a los ángulos del terreno previamente señalados con estacas. La intersec- 
ción de todas estas líneas formaba una figura semejante a la del terreno. También se podía situar el instrumento en el centro de éste y dividirlo en triángulos sin cambiar el punto de estación. Tiradas las visuales a los ángulos y trasladadas al borrador, era posible dibujar su perímetro si se conocía la longitud de todos los lados [Fig. 1].

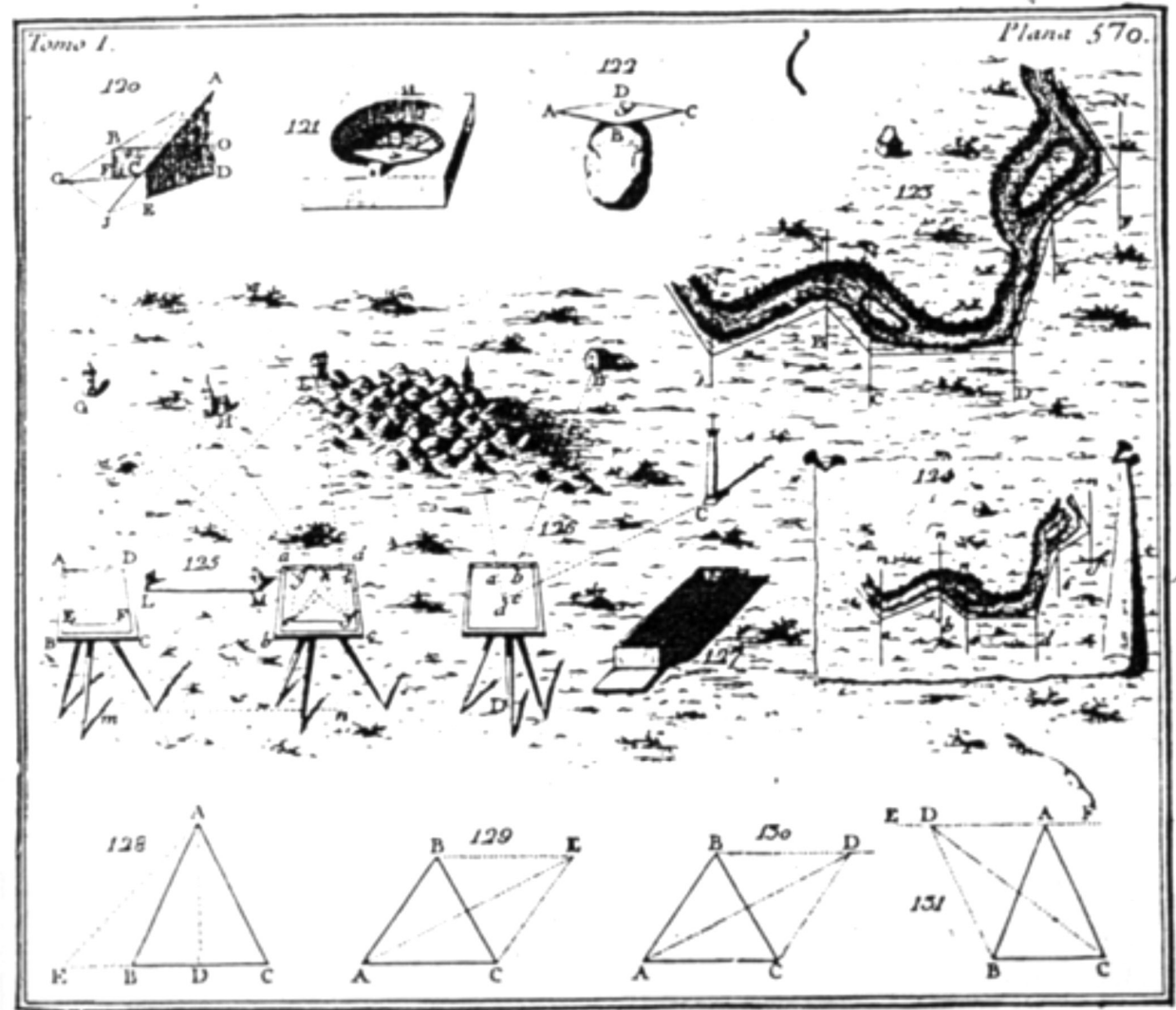

FIGURA 1. Instrucciones para el levantamiento de un plano con plancheta (B. Bails, Elementos de Matemática, 1793).

En todos los casos, la fiabilidad del plano dependía más de la exactitud de la medición que de la propia delineación. Los errores multiplicaban su importancia al trasladarse las líneas a escala, de ahí que fuera necesario comprobar el borrador sobre el terreno antes de pasarlo a limpio. Durante esta nueva inspección se calculaban todas las distancias necesarias para situar y dibujar con acierto los elementos geográficos y humanos de la zona. Así, el curso de un río se medía en el campo imaginando una recta paralela al mismo, desde la que se tiraban líneas perpendiculares a sus puntos sobresalientes (meandros, puentes, etc.). Dibujada en el papel, la longitud real de estas líneas se trasladaba a escala y daba lugar a una sucesión de puntos que, al unirse, formaba el cauce. Un mojón podía, de la misma forma, adquirir una posición relativa si se tomaba como referente cualquiera de las visuales. Por último, los accidentes del relieve se localizaban de forma arbitraria con el único fin de rellenar los huecos de la representación o reforzar la percepción individual del paisaje. 


\subsubsection{El trabajo de gabinete}

Aunque muchos de los mapas y planos de agrimensura no pasaron de la fase de borrador al formar parte de informes técnicos de uso limitado, un buen número de ellos recibieron una terminación más elaborada. En estos casos los apuntes tomados durante la visura o vista de ojos se comprobaban otra vez sobre el campo. Una vez en estudio, se orientaba el plano con ayuda de la brújula o las anotaciones tomadas sobre la salida y el ocaso del Sol y la situación de la Estrella Polar. Luego, se pasaba a limpio con ayuda de reglas graduadas y compases, y se lavaba. Para esto último se seguía un proceso común a toda la cartografía del siglo XVIII (Verkaven, 1811; Goulard, 1849):

a) El mejor papel era el de Holanda sin grano, blanco y batido, que se preparaba dándole una o dos manos de agua de alumbre en el caso de que no estuviera bien engomado.

b) Una vez listo, se observaban sus imperfecciones a contraluz, se humedecía por el revés con esponja, se pegaba a un tablero con cola y se dejaba secar.

c) A continuación, se colocaba el borrador encima del papel y se picaba con aguja el contorno del dibujo hecho en el campo. Si no se quería picar el borrador, se evitaba el paso anterior y se calcaba directamente sobre vidriera iluminada o papel transparente.

d) Las picaduras se hacían visibles repasándolas con carbón de pino o corcho molido y, luego, se retocaba el contorno con lápiz y se limpiaba el papel con miga de pan.

e) Se completaba el dibujo con los demás elementos del terreno y se le daba color. Para ello se utilizaban pigmentos disueltos en agua y extendidos con pincel, de ahí que se conozca como lavado del plano. Los colores principales se obtenían con tinta de China, carmín de París, azul de Prusia y gutagamba (amarillo) de la India. La tinta china servía para tirar las líneas y perfiles que no fueran obras de mampostería, incluyendo los marcos del plano, la escala y la carpintería (estacadas, puentes, etc.). Convenientemente disuelta en agua, con ella se oscurecían las zonas de umbría del relieve y las hondonadas del terreno y se pintaban las sombras de los objetos adoptando un foco de luz único para todo el plano. Con el carmín se daba color a las construcciones o fábricas (casas, cercas, techos, etc.), el azul servía para colorear los cursos de agua y el amarillo, por último, para indicar proyectos de obra y, sobre todo, de fortificación. La combinación de estos colores proporcionaba los restantes: con carmín y amarillo se obtenía el de arena (playas, islotes, etc.); con éste y el negro, se conseguía el de tierra (fosos, zanjas, surcos, etc.); con azul y amarillo se formaba, en fin, el verde (huertas, jardines, prados, etc.), que podía oscurecerse con añil para la representación de las copas de los árboles o de los matorrales.

f) Las plumas de cisne eran las recomendadas para trazar las líneas más gruesas (como los marcos del plano), pero para las demás se preferían las de cuervo o los tiralíneas. Los pinceles debían ser suaves, de punta no muy larga. Los pequeños se usaban para tomar los pigmentos, que luego se extendían con otros más grandes. Para desleír las tintas servían conchas de mar, aunque se aconsejaba la utilización de tacillas de vidrio.

g) Por último, para obtener copias sin picar el plano original se le superponía una cuadrícula formada con hebras de hilo o seda. También podía hacerse colocando entre las hojas necesarias un lienzo o cisquero con carbón molido y remarcando a continuación el contorno y los elementos más importantes de la figura representada en la primera de ellas (operación conocida como estarcir el plano). Si no se quería dañar el original, podía calcarse sobre cristal o sobre papel encerado con una mezcla de trementina o dándole un barniz de aguarrás [Fig. 2]. 


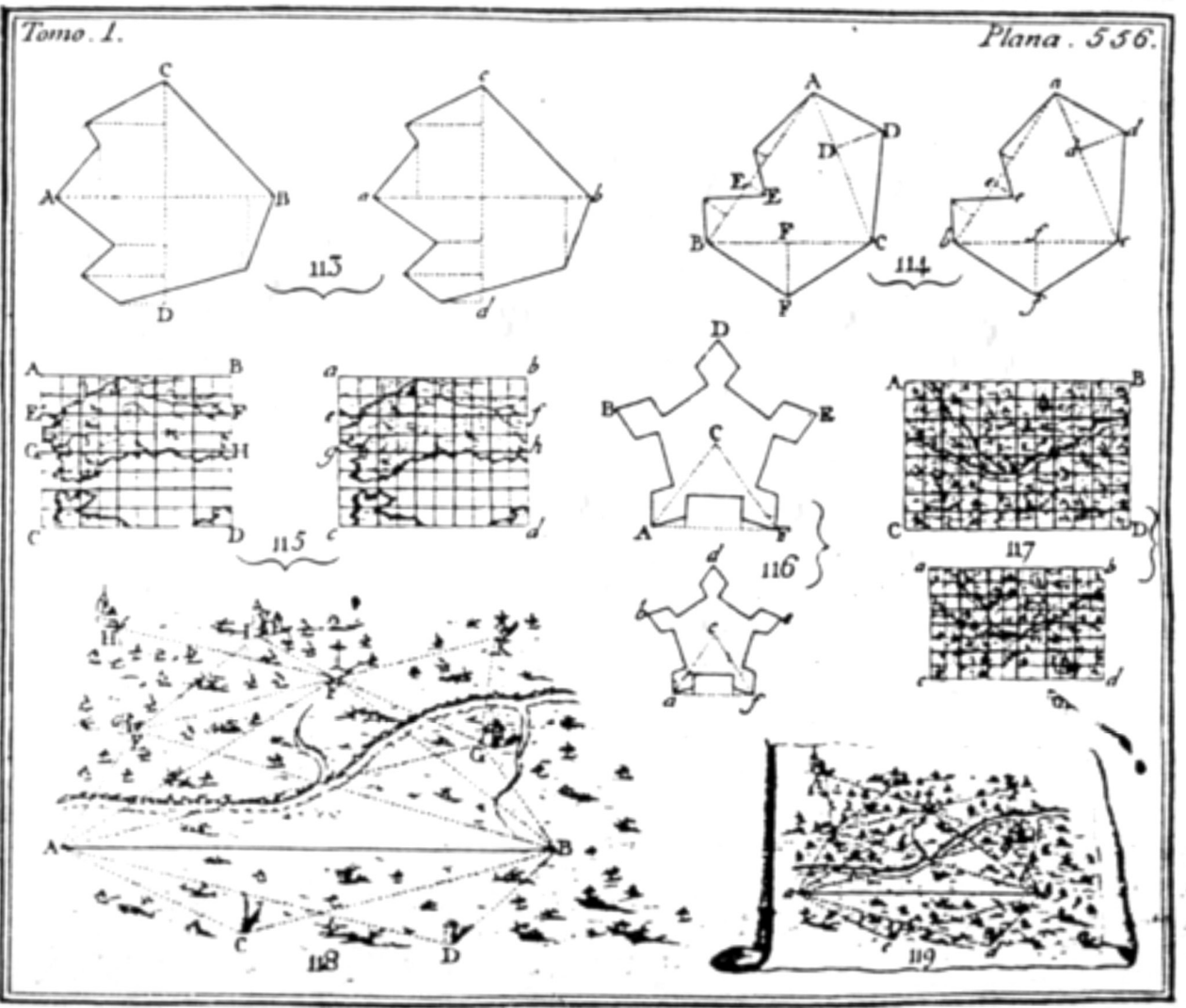

FIGURA 2. Instrucciones para la copia de planos en estudio (B. Bails, Elementos de Matemática, 1793)

Los trabajos realizados en estudio requerían de la posesión de cierta sensibilidad artística o, cuando menos, de una mínima habilidad para colorear a la aguada. Aunque algunos agrimensores valencianos cursaron estudios en la Sala de Flores de la Real Academia de San Carlos y se redactaron manuales especializados sobre el tema (como el Arte de pintar, de Gregorio Mayans), lo normal era que se buscase la colaboración de pintores profesionales. Gran parte del valor y de la legibilidad de los mapas y planos de agrimensura era mérito suyo aunque no los firmasen. De no darse esta colaboración y carecer el geómetra de las cualidades referidas, el levantamiento difícilmente mejoraba el borrador inicial. A lo sumo, se pasaba a tinta, pero no era infrecuente que se entregase a lápiz, incluso ante la Real Audiencia de Valencia y en la segunda mitad del siglo. El color acabó por convertirse en una exigencia, obligando con ello a cuidadosos trabajos de estudio.

\section{El agrimensor Francisco Aparisi y Ferrandis}

Aunque las leyes otorgaban competencias exclusivas a los titulados académicos, en la práctica este grupo se encontró bajo el tutelaje de los miembros de la generación intermedia de agrimensores valencianos (Juan Bautista Romero, José Soto, Tomás Casanova, José Cervera, etc.) Estos peritos tenían a mediados de siglo un prestigio profesional muy con- 
solidado y no necesitaron del preceptivo examen académico para seguir trabajando a partir de 1768. Formados en un ambiente paragremial que acabaron por superar, su contrastada experiencia les aseguró el acceso a los encargos más importantes del siglo. De todos ellos, fue Francisco Aparisi y Ferrandis (Valencia, 1732-1806) el agrimensor e hidrómetra que mejor supo adaptarse a los nuevos tiempos. Agrimensor titular de la ciudad de Valencia, acabó compaginando los encargos que le llegaban desde el municipio con la dirección de las obras de ampliación de la Acequia Real del Júcar y los trabajos para la Real Audiencia de Valencia que terminaron por convertirle en el perito en discordia de mayor renombre de la época. De esta actividad profesional se derivó una importante obra cartográfica de la que hemos podido localizar un total de quince piezas. A excepción de José Cervera y su interminable serie de perfiles de nivelación para las obras de la Acequia Real del Júcar (hecha bajo la atenta mirada de Aparisi), no existe otro agrimensor del siglo XVIII que haya dejado un rastro semejante.

\subsection{Datos biográficos}

Nacido en Valencia en 1732, Aparisi era el segundo hijo varón de un matrimonio de pequeños propietarios agrícolas formado por Francisco Aparisi (mayor), labrador de la huerta de Russafa, y por Silvia Ferrandis, originaria de Sollana. Según el reconocimiento de la siembra de arroces ordenado por el duque de Caylús en 1751, las posesiones familiares de origen paterno ascendían a 31 hanegadas de tierra situadas en Russafa, junto a la acequia del Vall y en la partida de Malilla, mientras que, de acuerdo con el sogueo de las parcelas empadronadas de la Acequia Real del Júcar de 1765-1767, la parte materna incluía otras 60 hanegadas de arrozal en la partida de la Alcaissia de Sollana. A pesar de este origen, todos los hermanos acabaron abandonando las tareas agrícolas (el mayor, José, era apoderado de los proveedores de carne en Valencia y el menor, Joaquín, acompañaba como ayudante a Francisco), lo que nos habla de una familia de subarrendadores que había ido mejorando progresivamente su situación social. De esta mejora puede dar idea el hecho de que sus miembros fueran familiares de la Santa Inquisición, honor que implicaba el reconocimiento público de su limpieza de sangre y constituía una fuente de ingresos (ligada a las delaciones) y de privilegios de clase.

Consecuencia de esta mejora debió ser el que Francisco Aparisi pudiera acceder a una formación regular bajo el magisterio del jesuita Antonio Eximeno, matemático de gran prestigio que impartía clases en el Seminario de Nobles de Valencia. La importancia de la educación que recibió se demuestra porque gracias a ella Aparisi pudo convertirse en agrimensor titular de la ciudad de Valencia en enero de 1764. Cuando en 1762 murió el veedor Luis Vidal y se abrió el debate en el ayuntamiento de Valencia sobre la necesidad de instaurar definitivamente el empleo de agrimensor, Aparisi, vecino de la ciudad al estar domiciliado en la céntrica calle de San Vicente, se apresuró a concursar presentando como aval la docencia de Eximeno. A diferencia de lo que ocurrió con el resto de los solicitantes (Mariano Castillo, José Rispo, Tomás Casanova y José Soto), el consistorio consideró que este aval era suficiente prueba de su capacidad y le liberó de pasar cualquier tipo de prueba, lo que demuestra indirectamente la impronta social de la familia Aparisi. Aunque apenas permaneció un par de años en este empleo, nunca rompió del todo una relación que le reportaría numerosos encargos en las décadas siguientes.

El motivo por el que abandonó el empleo municipal fue su contratación como hidrómetra por el duque de Híjar con motivo de las obras de ampliación de la Acequia Real del Júcar a partir de 1766. El encargo inicial se limitaba al sogueo de las tierras de Sollana que Juan de Roxas debía incluir en el mapa de la acequia que Casimiro Medina había dejado 
inacabado al morir a principios de 1764. El que este sogueo debiera comenzar en la partida de la Alcaissia, donde la familia conservaba algunas parcelas, fue probablemente la causa de que el duque se fijara en Aparisi. Su actuación debió agradarle, puesto que en 1768 Aparisi acompañó al ingeniero Juan de Escofet y al propio Juan de Roxas en las visuras que dieron lugar al proyecto de ampliación firmado por el primero de ellos. Cuando, después de cuatro meses de trabajo conjunto, Escofet tuvo que desplazarse a Lorca, Aparisi se hizo cargo de la dirección de las obras. Con las lógicas intermitencias debidas al lento avance del nuevo canal, en este cometido se emplearía hasta casi el mismo momento de su muerte en 1806. Cubrió dichas intermitencias con encargos alternativos que le llegaron desde el propio municipio y, sobre todo, desde la Real Audiencia de Valencia.

\section{2. Ámbitos de actuación}

El empleo de agrimensor municipal al que accedió Aparisi en 1764 fue creado como tal en 1737, cuando el catalán Antonio Cuyàs pasó la prueba práctica de acceso ideada por el impresor Antonio Bordázar. Lo ejerció hasta 1743, momento en el que fue sustituido por su hijo Carlos, quien acabó renunciando antes de que se convocase el concurso en el que participó Aparisi. La creación de este empleo se debió a la necesidad que tenía la ciudad de Valencia de solucionar los problemas que se le planteaban extramuros en el territorio de la Particular Contribución (formado por los cuarteles de Russafa, Benimaclet, Campanar y Patraix). Allí, a los trabajos de conservación de la red de acequias y caminos que seccionaba la huerta se unían tareas como la bonificación de aguazales o las derivadas de las controversias en torno a la propiedad de la tierra. En todos ellos debió de participar Aparisi, que acabó por especializarse en la nivelación de terrenos para la conducción de aguas, un apartado en el que continuaría trabajando después de dejar el cargo municipal. Junto al médico y catedrático Tomás Vilanova podemos encontrarlo en los siguientes años inspeccionando las lagunas del Grau y de Mont-Olivet en Valencia, la marjal de Orpesa y las fuentes de Chiva (Giménez, 2008: 230-239). Además, intervino continuamente en la visura de acequias y azudes y presidió la comisión que habría de dictaminar sobre la construcción de una presa en el río Turia a su paso por Gestalgar en 1778 (Faus, 1995: 105-107).

El prestigio como hidrómetra que le procuraron estas intervenciones, junto a la casualidad ya mencionada de poseer tierras en Sollana, acabaron por convertirle en el director de las obras de ampliación de la Acequia Real del Júcar desde el azud de Antella hasta el barranco de Catarroja (1769-1804). Durante más de treinta años y con la ayuda de José Cervera, dirigió unas obras que movilizaron a centenares de personas, supusieron el bautismo de fuego para decenas de futuros agrimensores y dieron finalmente riego a todas las tierras de secano situadas en torno a la Albufera. Con el respaldo ocasional de dos o tres ingenieros militares, Aparisi y Cervera mejoraron el canal que existía desde el siglo XIII (la Acequia Real de Alzira), lo rectificaron parcialmente y lo prolongaron algo más de veinticinco kilómetros. Hasta 1801, cuando se produjo la muerte de Cervera, el proceso que siguieron fue el siguiente:

a) Cervera y los maestros de obra Atanasio León y Jaime Miralles nivelaban la zona por donde debía discurrir la futura acequia.

b) En presencia de la comisión judicial que vigilaba el avance de las obras, Cervera presentaba su dictamen y lo acompañaba del perfil topográfico del terreno y de los planos de las construcciones necesarias.

c) Una vez aprobada la dirección propuesta, brigadas de peones excavaban el futuro canal. Por detrás de ellos, maestros de obra aseguraban el cauce y construían los edificios delineados. 
d) Cuando se completaba una nueva sección de la acequia, se procedía a la apertura de brazales e hijuelas para repartir el agua.

e) Aparisi, que también realizó personalmente algunas nivelaciones, vigilaba los gastos, contrataba con los proveedores las partidas necesarias y se encargaba de los detalles técnicos.

f) Además, desde 1769 se realizaban obras periódicas de reparación y desde 1780, limpiezas anuales del cauce. Los desbordamientos del río Júcar, que en 1786, 1791 y 1804 provocaron el derrumbe del azud de Antella, obligaron a revisar y reconstruir las defensas continuamente.

De todos estos trabajos se derivó un importantísimo fondo cartográfico, depositado actualmente en el Archivo de la Real Acequia del Júcar en Valencia, que puede atribuirse en buena medida a Aparisi, a pesar de que la mayoría de las piezas está firmada por Cervera (Faus, 2000). Ni que decir tiene que la experiencia acumulada en estas obras acabó reforzando la reputación de Aparisi como mapista e hidrómetra. Fruto de ella fue su continua contratación como perito en juicios que se seguían ante la Real Audiencia de Valencia. Este tribunal entendía sobre todo en causas de apelación, esto es, en aquellas que movilizaban grandes cantidades de dinero y se dilataban en el tiempo. En consecuencia, ante ella se dilucidaban pleitos de carácter territorial que exigían la contratación de un gran número de técnicos y la formación de planos muy detallados. La participación de Aparisi solía producirse como tercer perito en discordia cuando las partes no llegaban a un acuerdo satisfactorio. En estos casos, recomponía todo el proceso, efectuaba mediciones propias, contrastaba sus resultados con los anteriores y solía acabar levantando un nuevo plano que los contendientes debían aceptar como definitivo. A pesar de que las intervenciones documentadas de Aparisi ante la Real Audiencia son numerosas, la costumbre de reutilizar los planos en pleitos posteriores relativos a la misma zona y, por tanto, de agregarlos a un nuevo expediente, ha provocado que sólo haya llegado hasta nosotros media docena de los que debió realizar como consecuencia de ellas.

\subsection{Obra cartográfica}

\subsubsection{Mapas y planos localizados}

En la trayectoria profesional de Aparisi se pueden distinguir, en consecuencia, tres ámbitos de actuación, que quedan perfectamente representados por los quince mapas y planos que han llegado hasta nosotros [Anexo]:

a) Agrimensor municipal: aunque Aparisi trabajó en multitud de ocasiones para la ciudad de Valencia, su trabajo como agrimensor municipal fue muy corto (1764-1765). De esta etapa de su vida profesional únicamente conocemos un plano (Anexo, I; Fig. 3). Lo realizó en compañía de Bartolomé Olmos y fue el resultado de uno de los muchos pleitos por establecimientos ilegales que el municipio debió atender en la segunda mitad del siglo XVIII. Tuvo su origen en una iniciativa del comerciante Antonio Aparici, quien a comienzos de 1765 dirigió un memorial al ayuntamiento solicitando la concesión de 10 hanegadas incultas de la partida de La Punta en Russafa. Una vez que le fue aceptada esta demanda, repitió estas gestiones ante el intendente del reino con el fin de aumentar la superficie cultivable. En esta ocasión, solicitó permiso para cultivar un total de 634 hanegadas de realengo sitas en el paraje del Perú del mismo lugar, 427 de las cuales se hallaban en manos de intrusos. Esta petición fue evaluada por el Consejo de Hacienda, que recomendó que se le cediesen en enfiteusis sólo las 207 hanegadas que permanecían incultas, siempre 


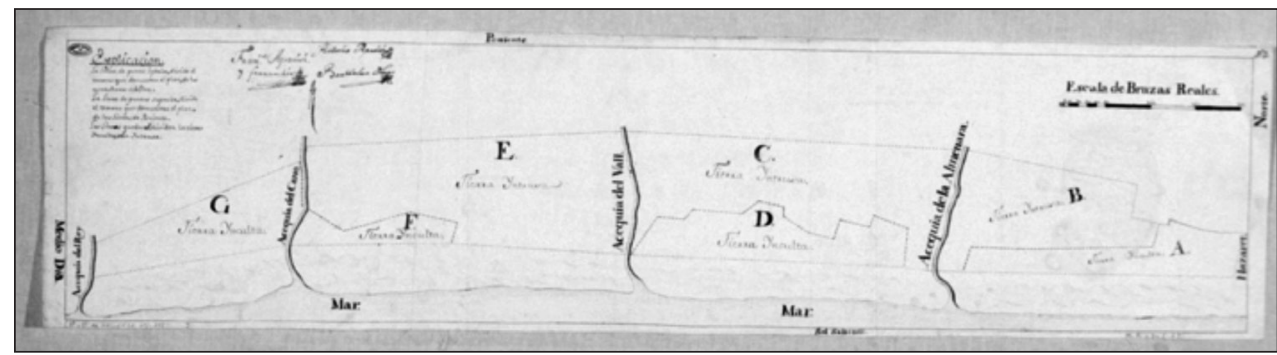

Figura 3. Aparisi, F. y Olmos, B.: [Plano de las tierras incultas en la huerta de Ruzafa, en el paraje llamado del Perú], [1765]. AGS.

que la población no las necesitase para pastos. El plano acompañaba a esta segunda solicitud e iba firmado, además de los geómetras, por el propio comerciante. Su finalidad era mostrar ante el Consejo de Hacienda la localización de las tierras y su vecindad con las municipales ya obtenidas.

b) Director de las obras de la Acequia Real del Júcar: de todo el fondo documental generado por estas obras, sólo seis piezas fueron firmadas por Aparisi: tres proyectos parciales, dos perfiles topográficos realizados en colaboración con Tomás Casanova, Bartolomé Rivelles y Jaime Miralles, y una visura del estado de las defensas ante posibles inundaciones (Anexo, II-VII). De ellas, sin duda las más interesantes son las que recogen las dos propuestas de Aparisi para la prolongación de la Acequia Real a partir del proyecto inicial de Juan de Escofet. En la primera, de 1770 (Anexo, II), proponía la rectificación del cajero antes de la extensión de los riegos más allá de Guadassuar y recogía las recomendaciones que Escofet le hizo llegar desde Lorca (la demarcación del cauce, la elevación de sus márgenes, la eliminación de las revueltas y la construcción de un camino paralelo al canal); en la segunda, de 1772 (Anexo, IV; Fig. 4), recogía el plan definitivo de obras que le fue aprobado por el Consejo General de la Acequia Real. La ejecución de este proyecto se demoró hasta 1778 ante la oposición de algunos de los municipios afectados (en Alzira y Algemesí se destruyeron las obras ya iniciadas), la continua presentación de quejas contra Juan Casamayor, juez comisionado por la Real Audiencia para vigilar el avance de los trabajos, y las dudas en torno al propio Aparisi, una vez desvinculado de Escofet.

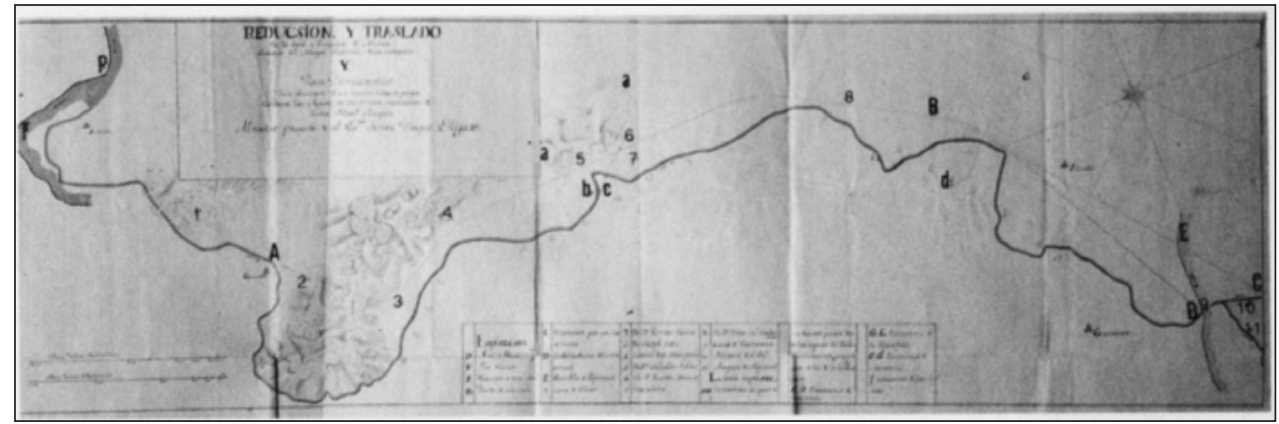

Figura 4. F. Aparisi: Reducsion y Traslado de la Real Azequia de Alzira, sacado del Mapa Grande de su Comuna (...), [1772]. ARX. 

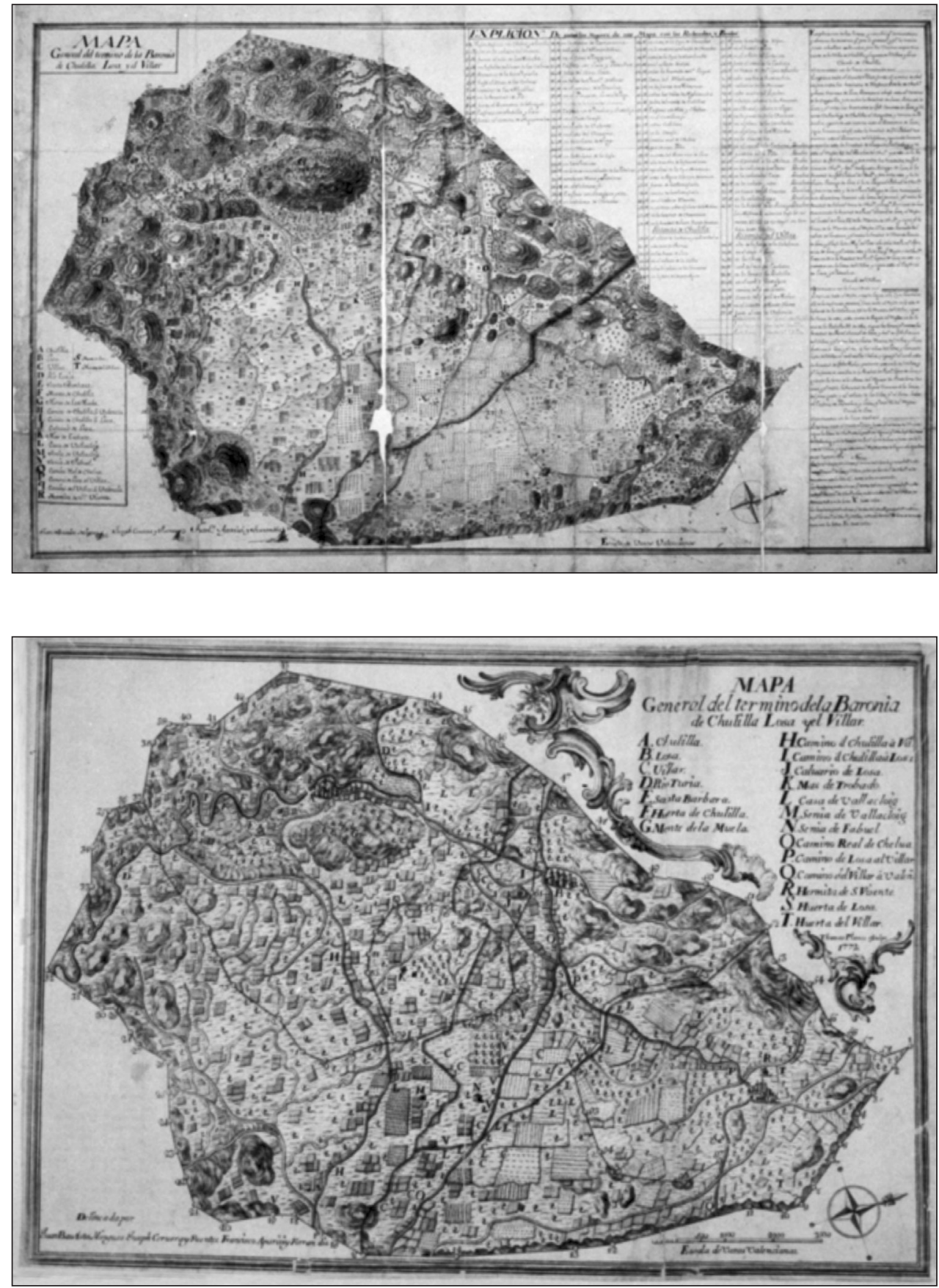

Figura 5. F. Aparisi, J. Cervera y J. B. Mínguez: Mapa General del termino de la Baronia de Chulilla, Losa y el Villar, [1770]. ARV. Original manuscrito (imagen superior) y mapa grabado por T. Planes e impreso por B. Monfort (imagen inferior). 
La situación se desbloqueó a finales de 1778, lo que permitió la rectificación y el ensanche del canal antiguo y, con la ayuda del ingeniero Baltasar Ricaud, la reedificación del azud de Antella. Hacia 1801, las obras estaban prácticamente acabadas. En 1780 alcanzaron el barranco de Algadins, cerca de Alginet; en 1783, el barranco del Motarró, entre Espioca y Almussafes; en 1785, el Fondo de la Coma; en 1793, las proximidades de Albal.

c) Agrimensor contratado: este apartado incluye un total de ocho planos, siete de los cuales responden a intervenciones como perito ante la Real Audiencia de Valencia y el restante a un proyecto de camino entre Valencia y Zaragoza que no hemos podido documentar (Anexo, VIII-XV). Entre los primeros se encuentran originales que responden a encargos recibidos de distintos nobles valencianos (el conde de Cocentaina, el marqués de Bèlgida, el barón de Llaurí y el conde de la Concepción), lo que da idea de las puertas que se le abrieron a Aparisi como resultado de su trabajo para el duque de Híjar. Aunque alguno de ellos guarda relación con su especialización como hidrómetra (la visura de la acequia de Quart de les Valls: Anexo, XIII), este conjunto de planos supone una pequeña muestra de los cometidos habituales que debían atender un agrimensor: deslinde de términos (Anexo, VIII, IX, X), establecimientos ilegales (Anexo, XI), divisiones de herencias (Anexo, XII), disputas territoriales (Anexo, XIV) y proyectos de obra (Anexo, XV). De todos ellos, sin duda el encargo más interesante para nosotros es el que dio lugar al único mapa de Aparisi que fue llevado a la imprenta (Anexo, VIII-IX; Fig. 5).

Este mapa fue el resultado de un pleito iniciado en 1770 por el lugar de Losa del Obispo para conseguir la condición de villa y su segregación respecto del de Chulilla. La resolución favorable a sus intereses, que incluía la obtención de un término jurisdiccional propio, acabó por alterar los límites internos de la baronía de Chulilla, señorío eclesiástico cedido por Jaime I a la mitra de Valencia del que también formaba parte el municipio de Villar del Arzobispo. Cuando Chulilla intentó que el término de Losa del Obispo quedase reducido al caserío habitado, la Real Audiencia forzó el nombramiento de los peritos que, en representación de las partes, debían actuar en el deslinde que ordenaba la sentencia. Aparisi actuó en nombre de Losa del Obispo y, junto a José Cervera y Juan Bautista Mínguez, empleó tres meses en la delineación del mapa, que fue presentado ante el escribano de la comisión judicial en agosto de 1770. Un año más tarde, los abogados de los tres municipios pidieron que se uniese a los ejemplares impresos de la sentencia y consiguieron la licencia del tribunal para separarlo del expediente y entregarlo a un grabador reputado. Según consta en un nota anexa al expediente, este traslado se produjo a finales de 1771 y el grabador elegido fue Tomás Planes. Finalmente, a comienzos de 1772, Benito Monfort se encargaría de su impresión.

\subsubsection{Características}

Los mapas y planos de agrimensura e hidrometría carecen de vida propia, no tienen sentido al margen del encargo que los motivó y del contexto en el que surgieron. Su inmediatez formal les impide poder trascender el momento de la delineación, ya que todas sus partes (el título, la leyenda, la numeración del expediente de referencia, las rúbricas, etc.) están condicionadas por el dictamen técnico de carácter jurídico del que formaban parte. Fuera de él se convierten en documentos inaccesibles. Estamos ante una cartografía estrictamente demostrativa, formal, definida por contraste con la descriptiva que acompañaba a las obras de geografía. Una cartografía que presenta las siguientes características generales: 
a) La finalidad utilitaria de mapas y planos forzaba el uso de grandes escalas. La representación de un campo de cultivo, del tramo de una acequia o de un camino vecinal obligaba a operar con escalas superiores al 1:1.000, pero incluso cuando se trataba de términos municipales o señoríos raramente se bajaba del 1:25.000. Estas escalas permitían la simplificación del simbolismo gráfico, que era sustituido, en gran parte, por la figuración de los objetos del terreno. Como resultado, mapas y planos eran muy accesibles para el lector, que los identificaba con una representación cuasi pictórica del paisaje. El aumento interesado de algunos hitos visuales permitía la comprensión rápida de la situación y la localización precisa del objeto del pleito o del proyecto.

b) La forma rectangular de mapas y planos remarcaba esta impresión al recoger la visión frontal del espectador. Esta disposición, asociada desde antiguo a la ordenación racional del espacio, estaba condicionada por la distribución de los cursos de agua (ríos, barrancos, acequias, etc.), que solían cruzar la delineación de parte a parte. El resultado eran piezas más anchas que altas cuya parte superior era ocupada por títulos excesivos. En los laterales solía situarse la leyenda, que en muchas ocasiones carecía de recuadro propio y se ajustaba a la representación. Cualquiera de los elementos de adorno que figuran en la cartografía geográfica (orlas, filacterias, etc.) se consideraba superfluo.

c) El contenido de mapas y planos respondía a un levantamiento topográfico incompleto. Aunque tanto la medición de ángulos y distancias como la nivelación de terrenos se incluían entre las operaciones habituales de agrimensura, rara vez coincidían estos tres datos en la cartografía derivada de ellas. Los perfiles de nivelación poseían escalas distintas para la altura y la longitud, pero no indicaban la dirección que seguían; los planos estrictos, por su parte, se limitaban a recoger los resultados de los trabajos topométricos (distancias y ángulos) y no mostraban los accidentes del terreno. Eran delineaciones planimétricas, en las que la superficie se consideraba plana.

d) El papel secundario jugado por el relieve denotaba la incapacidad del mapista agrimensor para representarlo. No era un problema exclusivamente suyo. Hasta la generalización de las curvas de nivel a comienzos del siglo XIX, toda la cartografía recurría en este campo al uso de diferentes técnicas de sombreado o, directamente, a recursos pictóricos que daban lugar a mapas perspectivos en los que la orografía era el resultado de una proyección horizontal y, a menudo, se limitaba a rellenar los huecos en una suerte de horror vacui. En suma, mapas y planos mostraban la localización y la sinuosidad de las montañas sin preocuparse de su altura.

e) Este olvido del relieve era resultado del carácter selectivo de la delineación. Al recoger normalmente problemas relacionados con la propiedad agraria, las zonas elevadas quedaban fuera del interés del mapista agrimensor. Eran los campos, los límites entre parcelas o la red de acequias los elementos que centraban su mirada. Sólo cuando se trataba de un deslinde o del reparto de una herencia cobraba el relieve auténtica importancia como elemento de referencia. El geómetra lo situaba entonces en la composición, pero con resultados muy heterogéneos: las zonas conocidas se representaban mediante sombras y focos de luz cenital, mientras que las montañas inaccesibles o poco recorridas se dibujaban en perspectiva caballera adoptando un punto de vista oblicuo o se sustituían directamente por alineaciones arbitrarias a la manera tradicional. El resultado de todo ello eran delineaciones que privilegiaban un paisaje totalmente humanizado. 
Como no podía ser menos, la obra cartográfica de Aparisi comulga con estas características. De hecho, la mayoría de sus piezas están encabezadas por el título mapa/plano/papel demonstrativo, término en el que fue pionero y que se relaciona con la interdependencia ya mencionada entre la cartografía y los dictámenes escritos a los que acompañaba. La práctica totalidad de ellas, además, poseen escala gráfica y utilizan como unidad la vara valenciana, en solitario o en combinación con la braza valenciana. Siempre utiliza grandes escalas, llegando a su máximo en el plano del casco urbano de Catarroja (1:800) (Anexo, XIV; Fig. 6). El uso habitual de la escala por parte de un agrimensor no es un asunto menor. Según pudimos comprobar hace tiempo a partir de una muestra de cien mapas y planos presentados ante la Real Audiencia de Valencia entre 1712 y 1808 , cerca de la mitad de ellos carecían de la misma (Faus, 1995: 242). La obra de Aparisi se adscribe, en este sentido, a las tendencias cartográficas modernas. De otro lado, todas sus delineaciones adoptan su estructura a elementos que las cruzan de lado a lado: la costa, el cauce de la Acequia Real del Júcar, los caminos de Chelva, Torrent y Zaragoza, el río Serpis, las acequias de Quart de les Valls y del Molí en Catarroja, y el barranco de Benimantell. Pero, sobre todo, donde se aprecia el carácter genuino de la cartografía de Aparisi es en el contenido altamente selectivo de su contenido.

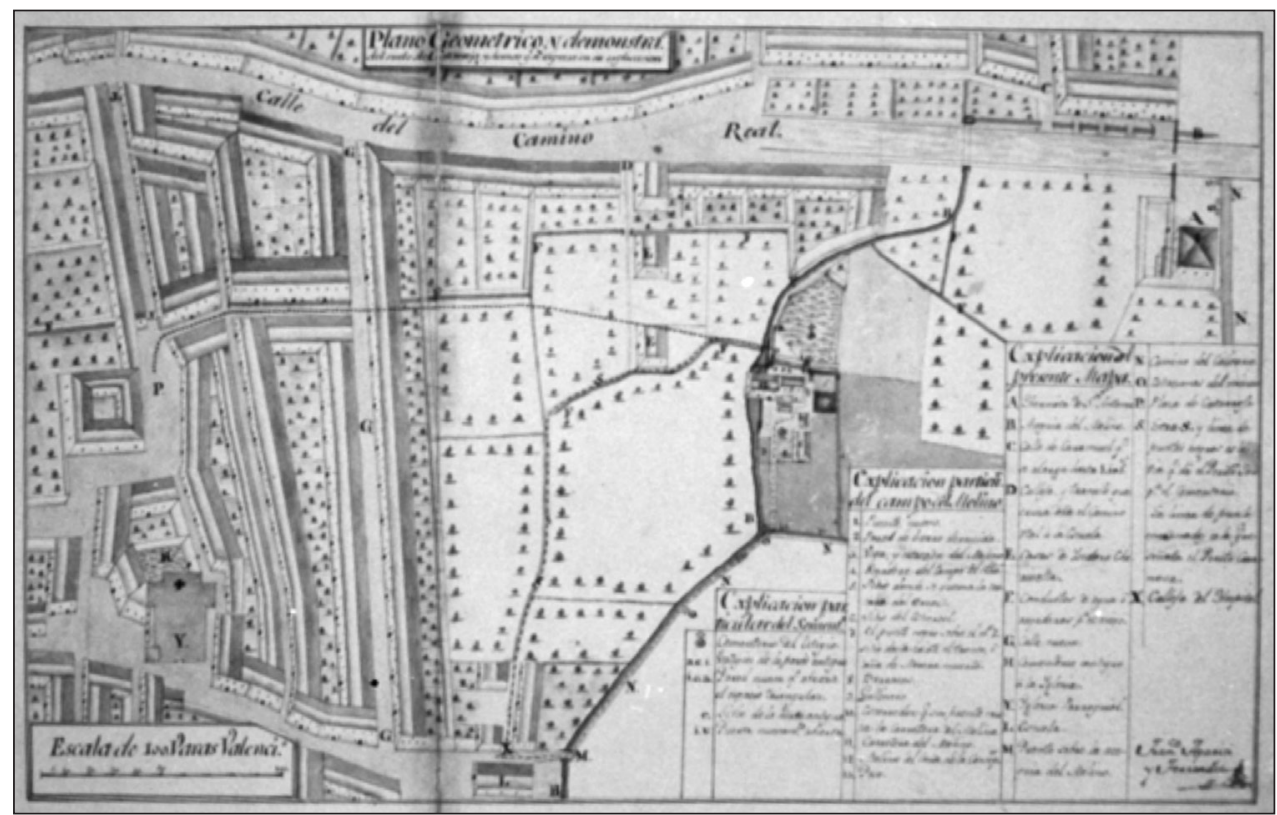

FIGURA 6. F. Aparisi: Plano Geometrico y demonstrativo del suelo de Catarroja, [1795]. ARV.

Aunque algunos de sus mapas y planos sean los que mejor recogen el relieve de entre los levantados por agrimensores en el siglo XVIII, tal apariencia no debe llevarnos a engaño. Aparisi actuó casi siempre como hidrómetra, de ahí que los elementos reflejados con mayor exactitud sean los cursos de agua. Si no podía ser de otra manera en los mapas y planos dedicados a la Acequia Real del Júcar, en los que nunca se refleja la topografía, este rasgo también puede apreciarse en los restantes. Los del condado de Cocentaina (Anexo, X; fig. 
7) y la baronía de Chulilla presentan cerros abancalados e iluminados desde un foco de luz cenital que se alterna con otro meridional. El resultado son cimas planas, individualizadas con tonos más claros que el de sus laderas. Sólo en las mayores alturas (la sierra de Mariola, por ejemplo) unos escarpes oscurecidos ofrecen el deseado contrapunto. El dedicado al término de Bellús, por su parte, está dominado por un relieve escenográfico, con la única excepción del tramo en el que el río de Albaida y el barranco de Benimantell lo vigorizan. En esas zonas aparecen simples líneas negras remarcadas con luz lateral que terminan en pequeñas paredes figurativas. Un análisis al trasluz de los mapas y planos de Aparisi permite reconstruir su método de trabajo. En estudio, nuestro agrimensor sólo trasladaba con detalle algunos hitos significativos (mojones, alquerías, etc.) y la forma de los cursos fluviales. Cada curva, cada meandro, cada confluencia, presentan rastros del picado del borrador, algo que es especialmente visible en los de la Acequia Real del Júcar, donde el cauce se descompone en tramos rectos. Ni uno solo de los cerros que los acompañan los poseen, dado que su inclusión se ajusta al trazado de los primeros y a la necesidad de cubrir toda la representación. Este carácter selectivo se aprecia también en el empleo del color. La paleta de Aparisi se limita a pigmentos ocres, grises y verdes de uso funcional. En el mapa del condado de Cocentaina, las sierras de Benicadell y Mariola se distinguen entre si porque la primera se representa en ocre y la segunda en gris. Y esta misma técnica la aplica en el mapa del término de Bellús a la distinción entre el río de Albaida y el barranco de Benimantell (en verde) y la red de barrancos secundarios que les acompaña (en gris). En el primero de ellos, además, individualiza los términos municipales gracias al empleo de distintos tonos de ocre.

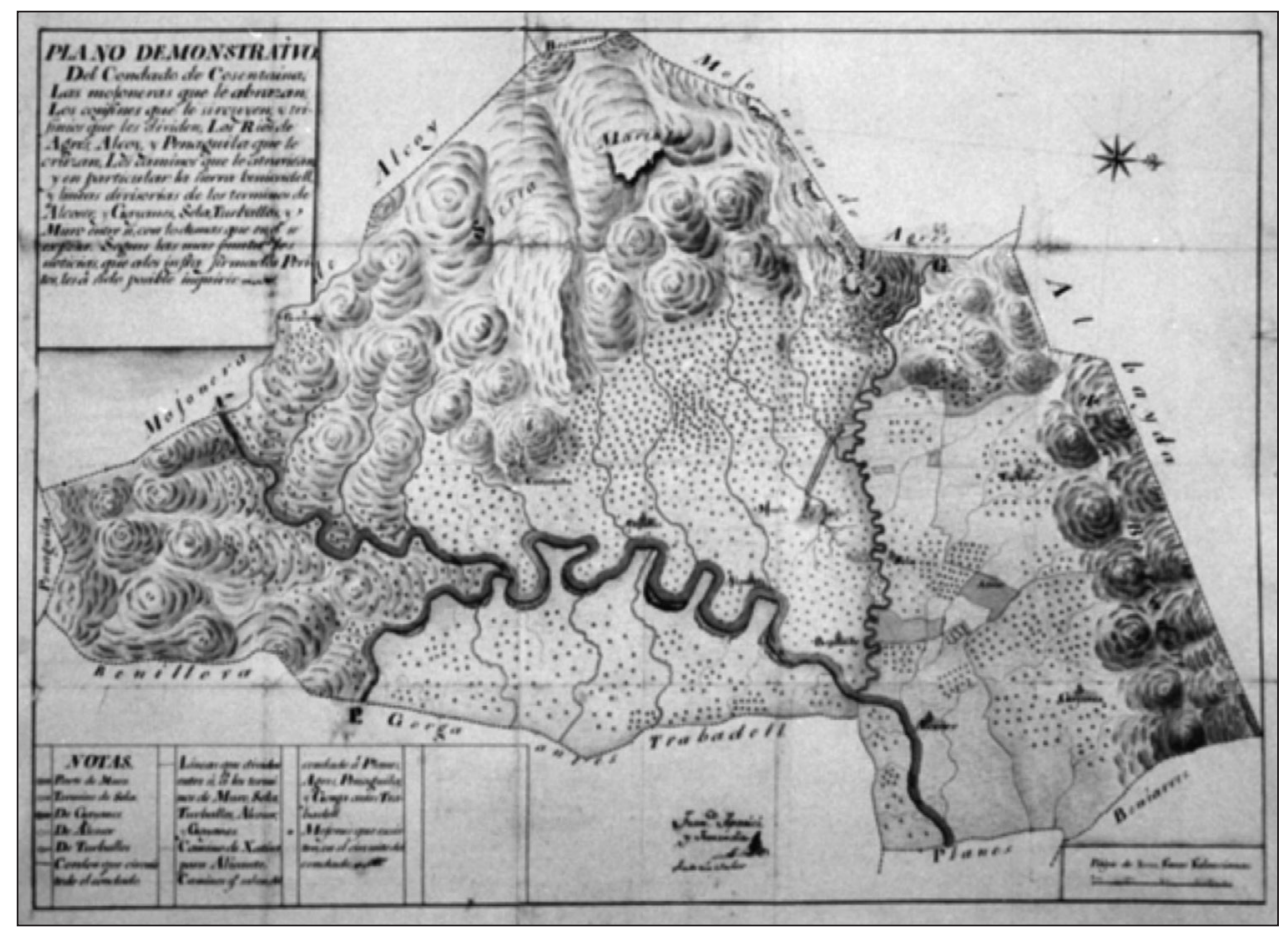

FIgURA 7. F. Aparisi y A. Valor: Plano demonstrativo del Condado de Cosentaina (...), [1778]. ARV. 
Junto a estos rasgos generales, la obra de Aparisi presenta otros particulares que permite identificarla. Así, la leyenda suele estar compuesta de letras (sólo se combinan con números en las piezas de la Acequia Real del Júcar), predilección que llega a ser agobiante en el mapa impreso de la baronía de Chulilla, donde los límites municipales son representados con una sucesión de ellas. Sin embargo, en ocasiones Aparisi deja sin explicar algunas de las letras (G, P y N en el mapa del condado de Cocentaina; J en el plano de Catarroja) y, en otras, simplemente se las salta en los índices ( $i$ !). También es propia de Aparisi la orientación de mapas y planos mediante rosa de vientos, así como el empleo de una simbología muy escasa. En este sentido, únicamente utiliza una sucesión de puntos para indicar los caminos, pequeñas líneas discontinuas para los límites administrativos, algunos árboles en las zonas cultivadas (incluyendo bancales accesibles), puntos aleatorios en barrancos sin interés y líneas paralelas muy marcadas y acompañadas de flecha en el sentido de la corriente en los cursos de agua. Por último, Aparisi introduce una toponimia ampliamente castellanizada, en la que destacan el empleo ortográfico de la y (Albayda, Alcoy, Gayanes, etc.) y de las alteraciones morfológicas habituales en el siglo XVIII (Torrente, Sagunto, Quarte, etc.). Esta castellanización alcanza incluso a la rúbrica: los planos de 1765 y 1770 los firma como Aparisi y Ferrandis; los posteriores, en cambio, como Aparici y Ferrándiz.

\section{Conclusión}

A lo largo del siglo XVIII se inició la sustitución de la cartografía ideográfica propia de la Edad Moderna por otra de contenido matemático más ajustada a las demandas contemporáneas (León, 2001). La cartografía de agrimensura e hidrometría constituye un ejemplo paradigmático en esta evolución. Preludio de la topográfica, de la que todavía la separaba su incapacidad para representar el relieve, su desarrollo se relaciona con las necesidades propias de la época, que hicieron que se encargara a los agrimensores el levantamiento de cientos de mapas y planos. Faltos de una formación regularizada, los hicieron trasladando directamente los resultados de las mediciones de campo a las delineaciones y adoptando las técnicas que aprendieron trabajando al lado de los ingenieros militares y los arquitectos. El resultado fue una producción que tendía a la uniformidad y en la que se fueron introduciendo, poco a poco, signos geométricos. El uso de la escala y del color, la independencia adquirida por la leyenda y la atención prestada a aspectos aparentemente superficiales como los títulos o las rúbricas prueban la influencia de estos colectivos mejor preparados. Los agrimensores, ajenos a cualquier inquietud científica, ocuparon un espacio profesional propio y pasaron a colaborar en el proceso de creación de la nueva cartografía que se abría paso.

Esta evolución puede seguirse perfectamente entre los agrimensores valencianos de la centuria. La comparación del trabajo de los primeros expertos en agricultura, acogidos a prácticas paragremiales que incluían la endotecnia como único cauce de formación, y del realizado por los agrimensores finiseculares, titulados académicos altamente especializados en campos como la hidrometría o el deslinde de términos, muestra unas diferencias tan acusadas que parece que estemos en presencia de dos colectivos distintos. Este cambio se aprecia fácilmente en su producción cartográfica. Frente a los escasos planos figurativos de principios de siglo, hechos sin atender a la escala, realizados a lápiz en la mayoría de las ocasiones y de difícil defensa como instrumentos legales, se pasó a un monumental fondo cartográfico formado por mapas y planos hechos a diferente escala, retocados en estudio y lavados a la aguada, que se incorporaron sin problemas a expedientes jurídicos y dictámenes técnicos. Entre los responsables de estos últimos se encontraban algunos de los mejores agrimensores del siglo (Tomás Casanova, Juan Bautista Romero, José Cervera, 
José Soto, etc.). La obra cartográfica de Francisco Aparisi y Ferrandis, estudiada en este artículo, ejemplifica a la perfección el trabajo de todos ellos.

\section{Bibliografía}

CAPEL, H. (1982): Geografía y Matemáticas en la España del siglo XVIII, Oikos-tau, Barcelona.

FAUS, A. (1995): Mapistes. Cartografia i agrimensura a la València del segle XVIII, IVEIAlfons el Magnànim, València.

FAUS, A. (2000): «Trabajos de hidrometría y cartografía en la Ribera del Xúquer y su Acequia Real (siglos XVI-XVIII)», en L'espai de l'aigua. Xarxes i sistemes d'irrigació a la Ribera del Xúquer en la perspectiva histórica, pp. 221-244, Universitat de València.

FAUS, A. (2001): «La Real Academia de Bellas Artes de San Carlos y el ejercicio de la agrimensura en la Valencia del siglo XVIII», en Asclepio, LIII-2, pp. 117-142, CSIC, Instituto de Historia, Madrid.

GIMÉNEZ, P. (2008): Las transformaciones del paisaje valenciano en el siglo XVIII, IVEIAlfons el Magnànim, Valencia.

GOULARD, H. (1849): Guide du géomètre pour les operations d'Arpentage et le rapport des plans, Bureau dels Annales Forestières, París.

HARLEY, J. B. (2005): La nueva naturaleza de los mapas. Ensayos sobre la historia de la cartografía, Fondo de Cultura Económica, México D. F.

HIJOSA, M. (1791): Compendio de Geometría práctica, con un breve tratado para medir terrenos, dividirlos y levantar planos arreglados a ellos, Imprenta Real, Madrid.

LEÓN, M. A. (2001): Desarrollo y evolución de la representación del territorio durante el siglo XVIII: de lo intuitivo a lo científico, Madrid, Eupalinos.

LUDOVICO, A. (1991): Rilevamento architettonico e topográfico. Metodi e strumenti nei secoli XVIII e XIX, Kappa, Roma.

THOMPSON, F. M. L. (1968): Chartered surveyors. The growth of a profession, Routledge $\&$ Paul, Londres.

THROWER, N. (2002): Mapas y civilización. Historia de la cartografía en su contexto cultural y social, Ediciones del Serbal, Barcelona.

VERKAVEN, J. J. (1811): L'Art de lever les plans, appliqué à tout ce qui a rapport à la guerre, à la navigation et à l'Architecture civile et rurale, Barrois L'Aine, París. 


\section{Anexo: Mapas y planos de Francisco Aparisi y Ferrandis}

\begin{tabular}{|c|c|c|c|}
\hline $\mathbf{N}^{\circ}$ & Plano & Localización & Documentación \\
\hline I & $\begin{array}{l}\text { [Plano de las tierras incultas, en el paraje lla- } \\
\text { mado del Perú de la huerta de Russafa], [1765]. } \\
\text { Con B. Olmos }\end{array}$ & AGS, I-49 & $\begin{array}{l}\text { AGS, Secretaría y Su- per- } \\
\text { intendencia de Ha-cienda, } \\
\text { Legajo } 110\end{array}$ \\
\hline II & $\begin{array}{l}\text { Puntual descripcion de las revueltas que forma } \\
\text { la Real Azequia de Alzira (...), [1770] }\end{array}$ & $\mathrm{ARX}, \mathrm{s} / \mathrm{c}$ & $\begin{array}{l}\text { ARX, Caja 23, Legajo } \\
15(1)\end{array}$ \\
\hline III & [Acequia de Sollana], [1771] & $\mathrm{ARX}, \mathrm{s} / \mathrm{c}$ & $\begin{array}{l}\text { ARX, Caja 24, Legajo } \\
\text { 16(1) }\end{array}$ \\
\hline IV & $\begin{array}{l}\text { Reducsion y Traslado de la Real Azequia de } \\
\text { Alzira, sacado del Mapa Grande de su Comuna } \\
(\ldots),[1772]\end{array}$ & $\mathrm{ARX}, \mathrm{s} / \mathrm{c}$ & $\begin{array}{l}\text { ARX, Caja 47, Legajo } \\
\text { 31(5) }\end{array}$ \\
\hline V & $\begin{array}{l}\text { Perfil cortado por la línea } 60,67 \text { y } 81 \text { del Mapa, } \\
\text { [1789]. Con T. Casanova y B. Rivelles }\end{array}$ & $\mathrm{ARX}, \mathrm{s} / \mathrm{c}$ & $\begin{array}{l}\text { ARX, Caja 51, Legajo } \\
33(3)\end{array}$ \\
\hline VI & $\begin{array}{l}\text { Plan Geometrico y demonstrativo del perjuicio } \\
\text { que el Rio ha causado en las huertas de Antella } \\
(\ldots),[1804]\end{array}$ & $\mathrm{ARX}, \mathrm{s} / \mathrm{c}$ & $\begin{array}{l}\text { ARX, Caja 29, Legajo } \\
\text { 19(4) }\end{array}$ \\
\hline VII & $\begin{array}{l}\text { Perfil de la Picadura entre Cano y Cano, [1805]. } \\
\text { Con J. Miralles }\end{array}$ & $\mathrm{ARX}, \mathrm{s} / \mathrm{c}$ & $\begin{array}{l}\text { ARX, Caja 115, Legajo } \\
78(10)\end{array}$ \\
\hline VIII & $\begin{array}{l}\text { Mapa General del termino de la Baronia de } \\
\text { Chulilla, Losa y el Villar, [1770]. Con J. Cer- } \\
\text { vera y J. B. Mínguez }\end{array}$ & ARV, 224 & $\begin{array}{l}\text { ARV, Registros de Escriba- } \\
\text { nía de Cámara, Expediente } \\
103,1793\end{array}$ \\
\hline IX & $\begin{array}{l}\text { Mapa General del termino de la Baronia de } \\
\text { Chulilla, Losa y el Villar, [1772]. Con J. Cer- } \\
\text { vera y J. B. Mínguez. Grabado por T. Planes }\end{array}$ & ARV, 225 & $\begin{array}{l}\text { ARV, Registros de Escriba- } \\
\text { nía de Cámara, Expediente } \\
\text { 103, } 1793\end{array}$ \\
\hline $\mathrm{X}$ & $\begin{array}{l}\text { Plano demonstrativo del Condado de Cosentai- } \\
\text { na (...), [1778]. Con A. Valor }\end{array}$ & ARV, 234 & $\begin{array}{l}\text { ARV, Registros de Escriba- } \\
\text { nía de Cámara, Expediente } \\
45,1765\end{array}$ \\
\hline XI & $\begin{array}{l}\text { Mapa demonstrativo del termino de Bellus } \\
(\ldots),[1785]\end{array}$ & ARV, 79 & $\begin{array}{l}\text { ARV, Bailía, Letra E, Expe- } \\
\text { diente } 1165\end{array}$ \\
\hline XII & $\begin{array}{l}\text { Papel demonstrativo de las dos heredades que } \\
\text { poseen Pedro Cavedo y D. Benito Escuder en } \\
\text { la Vega de esta Ciudad, partida del camino de } \\
\text { Torrente, }[1788]\end{array}$ & ARV, 282 & $\begin{array}{l}\text { ARV, Registros de Escriba- } \\
\text { nía de Cámara, Expediente } \\
181,1788\end{array}$ \\
\hline XIII & $\begin{array}{l}\text { Plano demonstrativo de las fuentes de Quarte y } \\
\text { division de sus aguas en los Balles de Sagunto, } \\
\text { [1792] }\end{array}$ & ARV, 100 & $\begin{array}{l}\text { ARV, Bailía, Letra E, Expe- } \\
\text { diente } 1347\end{array}$ \\
\hline XIV & $\begin{array}{l}\text { Plano Geometrico y demonstrativo del suelo de } \\
\text { Catarroja, [1795] }\end{array}$ & ARV, 277 & $\begin{array}{l}\text { ARV, Registros de Escriba- } \\
\text { nía de Cámara, Expediente } \\
40,1792\end{array}$ \\
\hline XV & $\begin{array}{l}\text { [Proyecto de camino entre Valencia y Zaragoza } \\
\text { pasando por Morella], [1795] }\end{array}$ & SHM, 2599 & ------ \\
\hline
\end{tabular}

Abreviaturas: AGS: Archivo General de Simancas (Valladolid); ARX: Archivo de la Real Acequia del Júcar (Valencia); ARV: Archivo del Reino de Valencia (Valencia); SHM: Servicio Histórico Militar (Madrid); s/c: sin clasificar. 